\title{
Comportamiento del consumidor
}

\section{Consumer behavior}

Guadalupe S. Ramírez-Sánchez ${ }^{a}$, Kenia E. García-Cruz ${ }^{b}$, Heber J. Ortiz-González ${ }^{c}$ \begin{abstract}
:
In this work we are going to see the most relevant factors in the marketing area, concentrating specifically on the issue of consumer behavior and what are the factors that most influence this to be carried out, as well as some aspects to consider for excellent results in the organization and / or company.
\end{abstract}

\section{Keywords:}

Behavior, company, consumer, marketing

\section{Resumen:}

En este trabajo vamos a ver de los factores más relevantes en el área de la mercadotecnia, concentrándonos específicamente en el tema del comportamiento del consumidor y de cuáles son los factores que más influyen para que este se lleve a cabo, al igual de algunos aspectos a considerar para unos excelentes resultados en la organización y/o empresa.

\section{Palabras Clave:}

Comportamiento, empresa, consumidor, marketing

\section{Introducción}

El estudio del comportamiento del consumidor se origina de la definición actual del marketing que se centra en las necesidades del consumidor. Difícilmente podríamos satisfacer de forma correcta las necesidades del cliente, tanto el actual como el potencial, sin un conocimiento previo de los bienes y servicios que desea y de las actividades que realiza para adquirirlos. Por tanto, la tarea del marketing es comprender, explicar y predecir las acciones relacionadas con el consumo.

El comportamiento del consumidor se refiere a las actividades que realiza una persona o una organización desde que tiene una necesidad hasta el momento en que realiza la compra y usa después el producto. El estudio de tal comportamiento incorpora el análisis de todos los factores que intervienen en las acciones realizadas.

\footnotetext{
${ }^{a}$ Universidad Autónoma del Estado de Hidalgo, https://orcid.org/0000-0002-0992-2955, Email: ra443666@uaeh.edu.mx

b Autor de correspondencia, Universidad Autónoma del Estado de Hidalgo, https://orcid.org/0000-0003-0150-2080, Email: ga383965@uaeh.edu.mx 

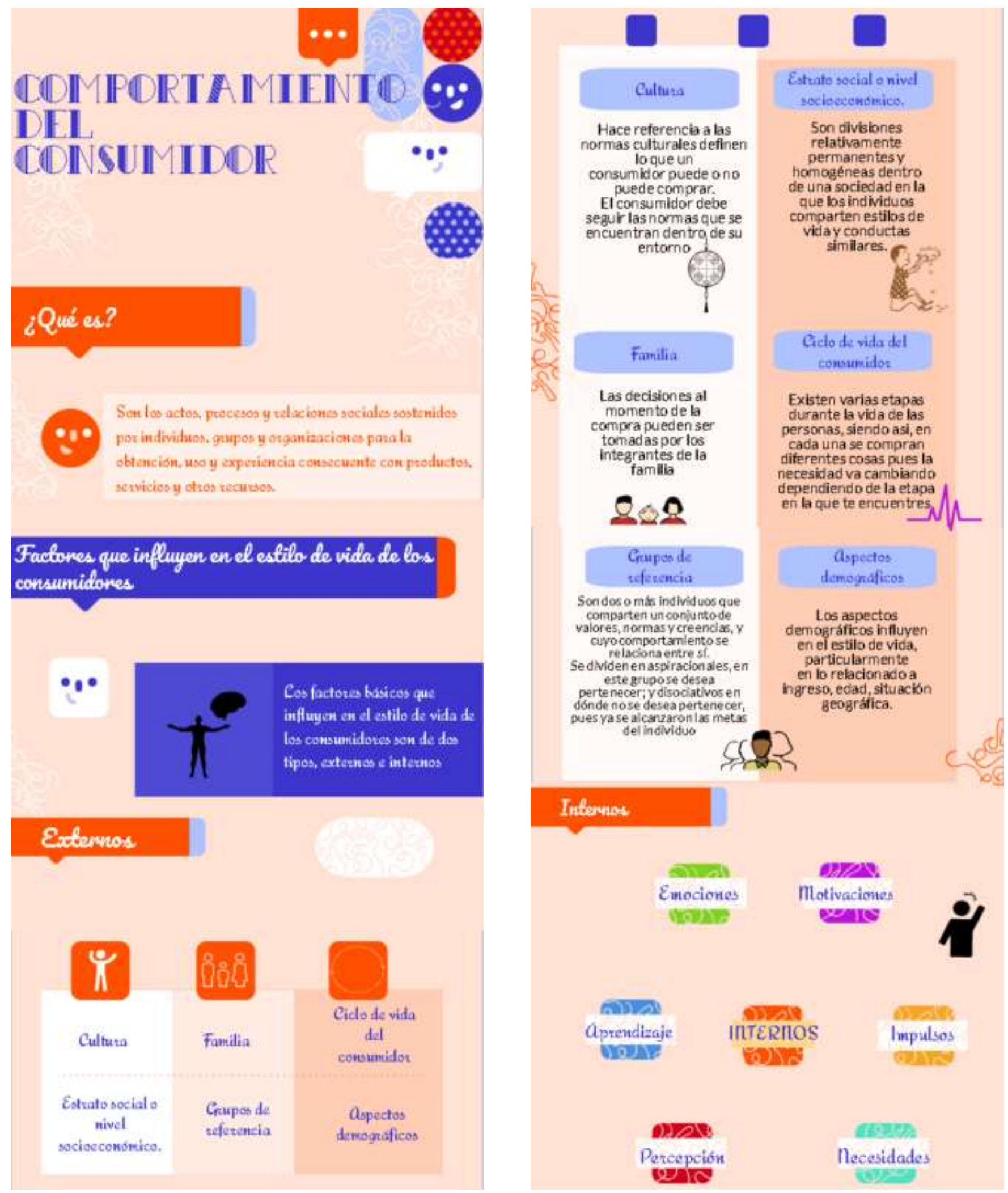


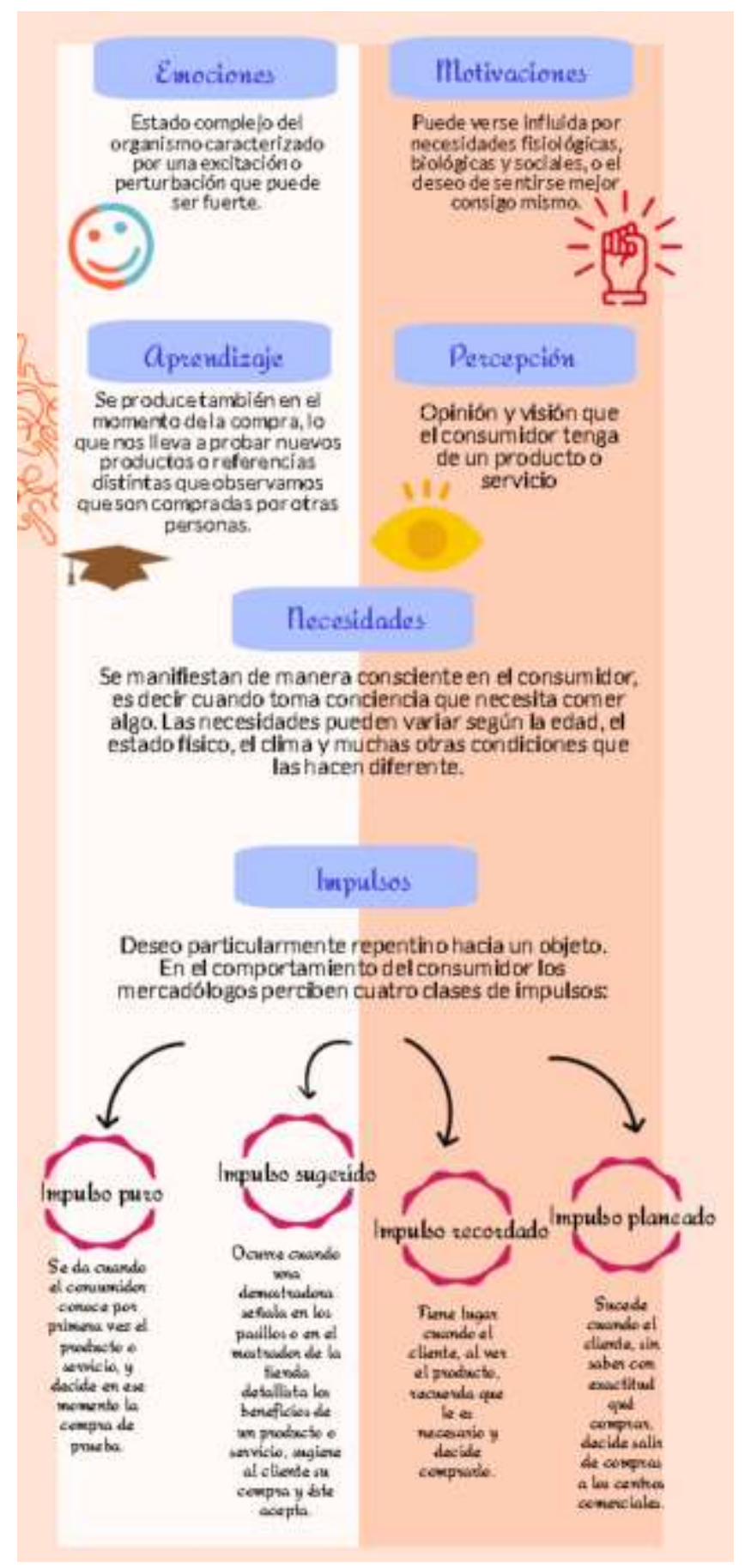

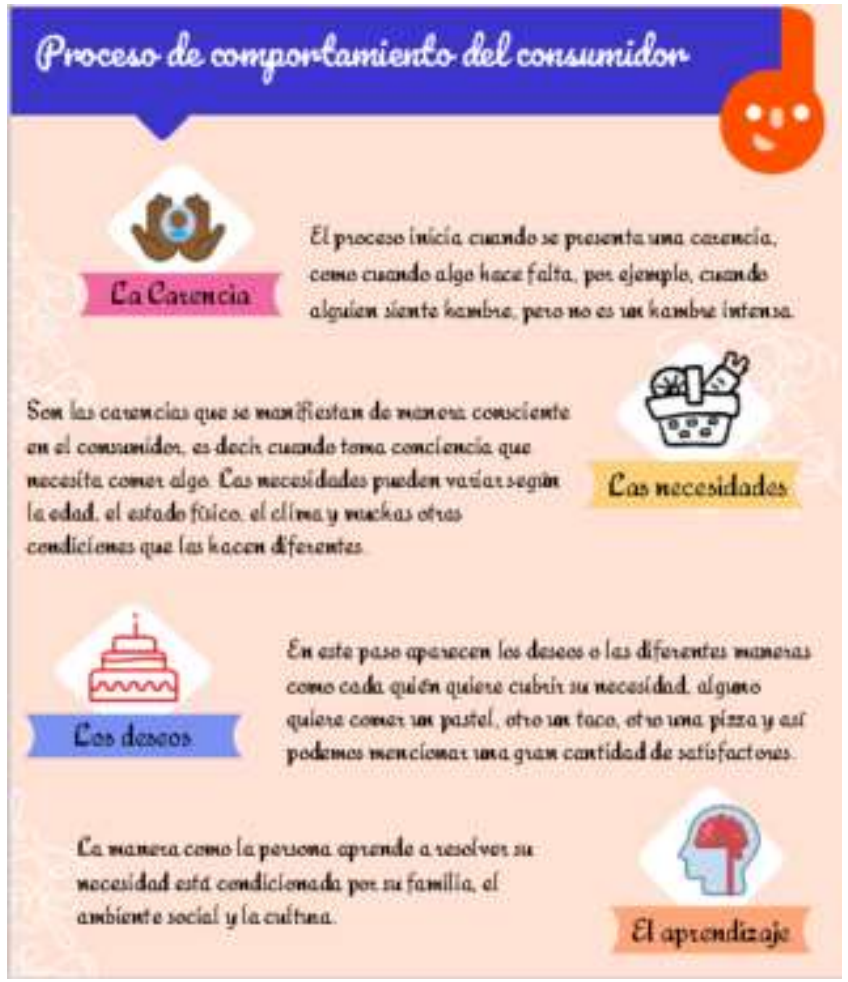

\section{Referencias}

[1] Sánchez, D. (2015). Comportamiento del consumidor en la búsqueda de información de precios on-line. Madrid: Facultad de Ciencias Económicas y Empresariales Universidad Autónoma de Madrid.

[2] Fisher, L., \& Espejo, G. (2017). Mercadotecnia (5 ed.). Ciudad de México: Mc Grae Hill.

[3] Salinas, K., \& León, W. (2016). Comportamiento de compra del consumidor de bares de coctelería en la ciudad de Trujillo. Tesis, Universidad Privada del Norte., Trujillo.

[4] Pérez, A. (18 de agosto de 2017). Mercaktiva. El blog de Mercadotecnia.

[5] PuroMarketing, (2019), "El nuevo consumidor digital-first y los cambios de comportamiento en su relación con las marcas"

[6]Myriam Quiroa (25 de julio, 2019). Comportamiento del consumidor. Economipedia.com

[7] Rodríguez, P, Sergio, (2021). Consumidor consciente. Un recorrido por su toma de decisiones, Ed. Esic.

[8] Solomon R, Michael, (2017). Comportamiento del consumidor, décima edición, Ed. Pearson.

[9] Schiffman, León, (2018). Comportamiento del consumidor, décima edición, Ed. Pearson. 